\title{
СОВРЕМЕННЫЕ ПРОБЛЕМЫ ОРГАНИЗАЦИИ ЗРИТЕЛЬНОЙ РАБОТЫ В СИСТЕМЕ ОБУЧЕНИЯ НА КАФЕДРАХ ГИГИЕНИЧЕСКОГО ПРОФИЛЯ
}

В настоящее время во многих странах мира весьма актуальна проблема пониженной остроты зрения среди населения. Одним из путей преодоления неблагоприятных тенденций в этом направлении является рациональная организация зрительной работы для представителей всех без исключения профессиональных и возрастных групп.

Опыт показывает, что информированность молодого поколения о рациональной организации освещения недостаточна. В программе обучения на кафедре гигиены и экологии ГОО ВПО «ДОННМУ ИМ. М. ГОРЬКОГО» предусмотрен ряд тем, затрагивающих вопросы гигиены зрительной работы. Тем не менее, не удается осветить в должном объеме все особенности, понимание которых необходимо будущим врачам. Решение проблемы, на наш взгляд, возможно за счет увеличения количества академических часов на темы, в структуру которых входят вопросы гигиены зрительной работы.

Опыт показывает, что некоторые фрагменты материала студенты осваивают недостаточно хорошо. Например, гигиенические требования к освещению и гигиеническое нормирование. Правильное понимание данных проблем особенно важно для будущих специалистов именно лечебного профиля. В перспективе, им предстоит самостоятельно организовывать, и, впоследствии, оценивать условия зрительной работы на своем рабочем месте без использования инструментальных методов изучения и оценки производственного освещения. Рассматривая ситуацию самостоятельной подготовки студентов к занятиям, хотелось бы особо отметить полное отсутствие какого-то контроля со стороны специалистов санитарно-эпидемиологической службы, поскольку, санитарный врач не имеет возможности осуществлять контроль за условиями зрительной работы в жилищах, тем более в вечернее время. Студенты в полной мере осознают важность проблем гигиены зрения, поскольку очень хорошо понимают, что современные технологии существенно меняют специфи- ку нагрузки на зрительный анализатор врачаклинициста, а это, в свою очередь, обусловливает повышение значимости сохранения остроты зрения на должном уровне.

Обеспокоенность преподавателей вызывает еще одно важное обстоятельство. Недостаточно полное понимание студенты, также, демонстрируют при интерпретации и оценке условий освещения рабочего места, серьезные затруднения вызывают вопросы размещения рабочего места относительно источников света, как при естественном, так и при искусственном освещении. Причина этого, по нашим наблюдениям, в формировании у студентов фрагментарного понимания целого ряда проблем по направлению «Гигиена зрения и зрительной работы». Для формирования у студентов целостного представления о проблеме, мы считаем необходимым увеличить количество времени на рассмотрение данных вопросов.

Актуальность обсуждаемой темы обостряется еще и в связи с тем, что новые технические решения становятся причиной появления новых проблем. В условиях современного информационного изобилия даже специалисты, далеко не всегда имеют возможность получать объективную информацию о различных новых видах современных технических устройств.

Например. Одним из таких видов техники являются светодиодные лампы. В настоящее время они получают все более широкое распространение.

Причиной выбора светодиодных ламп для освещения жилых помещений являются некоторые светотехнические характеристики данного вида источников света. А именно. Потребление электроэнергии светодиодной лампой в 7-10 раз меньше, чем лампой накаливания. Светодиоды долговечны. Их срок действия до 50 тысяч часов непрерывной работы. Они не вре-

(c) А.А. Потапов, М.И. Ежелева, 2019

(c) Университетская Клиника, 2019 
дят окружающей среде и с ними удобно создавать осветительные системы любого назначения. Главное достоинство ровный неяркий свет высокого качества.

В определенный период времени были опубликованы результаты исследований, свидетельствующие о благоприятном воздействии светодиодного освещения. Направленность данных исследований имела характер сравнения двух видов источника света - светодиодных ламп и люминесцентных ламп.

Были сделаны выводы о более благоприятной световой среде и менее выраженных неблагоприятных реакциях со стороны зрительного анализатора [1]. При этом отмечены менее выраженные неблагоприятные реакции и со стороны других систем.

Весьма любопытны результаты сравнительного анализа функционального состояния организма, формирующегося в процессе обучения школьников начальных, средних и старших классов [2]. Авторами сделаны выводы о меньшей физиологической стоимости учебных нагрузок в случае использования в классах светодиодных источников света. Сравнительно с условиями при освещении люминесцентными лампами, были отмечены более высокие значения количественных и качественных показателей умственной работоспособности и меньшей в 2-2,5 раза частотой случаев выраженного утомления. Причем, как в начальных, так и в старших классах, а также и на протяжении всей учебной недели. Функциональное состояние зрительного анализатора, в том числе и аккомодационного аппарата глаза, независимо от возраста, было стабильнее при светодиодном освещении. Опять же, при светодиодном освещении отмечено лучшее психоэмоциональное состояние. Причем, и учащиеся, и педагоги субъективно оценили условия при светодиодном освещении, как более комфортные.

Преимущества светодиодных источников света были обнаружены и в случае организации работы с использованием компьютерной техники $[1,2]$.

При исследовании учащихся младших классов [3] установлено также, что светодиодное освещение по сравнению с люминесцентным приводит к достоверному ослаблению негативных изменений функциональной лабильности зрительного анализатора, силы возбуждения нервной системы и когнитивных функций, а также к усилению позитивных изменений психомоторики.

Таким образом, полученные разными авторами результаты позволяют рекомендовать светодиодные источники света для применения в современных учебных заведениях.
Однако, рассматривать применение светодиодов как один из вариантов гигиенической оптимизации условий зрительной работы всетаки не стоит. Результаты, полученные другими авторами, а также материалы более поздних исследований показывают, что имеются веские, с гигиенических позиций, причины для ограничений в использовании данного вида источника света.

В частности. Искажение цветопередачи и увеличение диаметра зрачка. Причина - большая доза синего света в спектре излучения, в том числе и у светодиодов белого света. В этой связи следует особо отметить, что данная информация представлена в специализированных изданиях, поэтому риски для здоровья человека далеко не всегда оцениваются адекватно. Например, при ежедневном воздействии синего света на глаза, в подростковом возрасте, может развиться дегенерация сетчатки к тридцати годам $[4,5]$.

Оценивая особенности воздействия светодиодных светильников на организм, хотелось бы акцентировать внимание на тех моментах, которые при оценке освещения, как санитарнотехнической системы, обычно ускользают от внимания, в том числе и специалистов, работающих в практическом здравоохранении.

В частности. Преобладание в спектре синего света подавляет выработку мелатонина. Поскольку мелатонин является активным антиоксидантом, возникают изменения не только со стороны зрительного анализатора [4].

Не менее важен значительный выброс кортизола. Отмечается более чем двукратное превышение выработки этого гормона. Поскольку кортизол является регулятором углеводного обмена, способствует сохранению энергетических ресурсов организма, а также принимает участие в развитии стрессовых реакций («гормон стресса»), можно констатировать наличие генерализованной реакции на воздействие излучения светодиодных ламп. Таким образом, имеется патофизиологический фон для гормональных сдвигов. В свою очередь, это является причиной повышения чувствительности к изменениям магнитного поля, а также биоритмологических нарушений $[4,6]$.

Данное обстоятельство обусловлено еще и тем, что отмечается наличие пульсирующего магнитного поля в среде обитания. Кроме того, результаты исследований [4] свидетельствуют о том, что в связи с биоритмологическими особенностями организма человека не рекомендуется выполнять зрительную работу, с использованием светодиодов, после 19 часов.

Подтверждением того, что даже специалисты 
не имеют полной информации по данной проблеме, является тот факт, что нормативы, разработанные для люминесцентных ламп, безосновательно используются при гигиенической оценке светодиодного освещения. При этом необходимо подчеркнуть, что в результатах исследований, опубликованных разными авторами, выводы имеют противоречивый характер.

В современных условиях важнейшей составляющей зрительной работы является использование компьютерной техники, в частности видеодисплейных терминалов. Условия зрительной работы всегда признавались наиболее значимыми с точки зрения гигиены и физиологии труда. Однако, при этом, опять же, некоторые нюансы недооцениваются большинством специалистов-практиков.

Например. О специфичности изображения на экране видеотерминала знают все. При этом, недостаточно полно оцениваются риски для организма в целом, поскольку противоестественность изображения для природы зрительного анализатора не принимается во внимание при оценке трудового процесса. В частности, заслуживают отдельного упоминания следующие характеристики изображения. Необычный контраст между фоном и символами на экране, при наличии периодического мерцания; изображение на экране является самосветящимся, тогда как человек адаптирован к восприятию изображения только в отраженном свете; изображение формируется дискретными точками или линиями растра, тогда как человек адаптирован к восприятию целостного изображения; значение яркости изображения подвержено колебаниям внутри одного символа (знака). В этой связи уместно вспомнить результаты, опубликованные группой экспертов ВО3 [7]. Результаты последующих исследований, в том числе и современных [8, 9], свидетельствуют о специфичности реакций зрительного анализатора, обусловленных особенностями изображения, предъявляемого на экранах видеотерминалов. Кроме того, отмечены типичные изменения психофизиологического состояния и стресс-реакции, в том числе и у подростков [10].

Современные технологические решения позволили нивелировать осознанное восприятие перечисленных особенностей. Но никуда не исчезло их подсознательное, подкорковое восприятие. Данное обстоятельство нам представляется особенно важным. Необходимо подчеркнуть, что факторы трудового процесса, в отличие от факторов производственной среды, практически не изменяются $[7,8,11]$. Их количество и характеристики мало зависят от модификаций компьютерной техники. При этом, роль именно факторов трудового процесса в формировании специфических функциональных состояний является ведущей [11].

В этой связи, хотелось бы особо отметить, что многие виды отдыха, требующие напряжения зрительного анализатора, с точки зрения гигиены и физиологии труда являются работой, и могут быть причиной, не только ухудшения функционального состояния, но и патологии. Однако, в представлении большинства наших современников любые виды деятельности в нерабочее время оценивается как вариант отдыха. Например, просмотр телепередач, занятия компьютерными играми и прочие варианты организации досуга. При этом, даже студентымедики, после детального анализа и подробных объяснений, не всегда в полной мере отдают себе отчет в том, что отдых, который считается таковым с точки зрения трудового законодательства и распределения времени в течение суток, может оказывать воздействие на организм даже более выраженное, чем производственная нагрузка.

Например. В последнее время наметилась тенденция к повышению интереса у студентов к чтению художественной литературы. Студенты для чтения обычно используют такое устройство как ридер. Довольно-таки часто бывают случаи чтения с ридера, в том числе и во время перерывов. Поскольку имеет место отвлечение от предмета, изучаемого на кафедре, студенты пребывают в полной уверенности, что, именно таким образом, осуществляется процесс отдыха. Однако, при этом формируется повышенная эмоциональная напряженность [12]. Кроме того, отмечается [13] ухудшение функции оперативной памяти. То есть речь идет, не только о влиянии специфических гигиенических особенностей изображения, но и о снижении качества усвоения учебного материала.

Проблема усугубляется еще и тем, что информация о характеристиках ридера, которую легко найти в сети Internet, зачастую представляет материал тенденциозно, сглаживая острые, в гигиеническом отношении, моменты. Естественно, сайты, доступные широкому кругу пользователей, не дадут информацию, которая представлена в серьезных научных изданиях. Например, о том, что при использовании ридера, в сравнении с бумажными носителями информации, отмечается сохранение повышенной активации ЦНС после завершения чтения, что говорит о более выраженном утомлении [12].

Отдельная тема - отдых с использованием компьютерных игр. С точки зрения гигиены и физиологии труда, игра за компьютером - это работа за компьютером. Однако ставить меж- 
ду этими понятиями знак равенства нельзя, поскольку в процессе работы человек отдает себе отчет в том, что он именно работает. Все хорошо знают, что в работе должны быть перерывы. Если же речь идет об игре, то психологически это воспринимается как отдых. Тем более, что в игре человек мотивирован. Стремление достичь желаемого результата и потом улучшить его, зачастую приводит к тому, что человек, отведя на отдых 10-15 минут, проводит за игрой несколько часов. Естественно, что в течение этого времени формируется и накапливается переутомление. Причина в воздействии на пользователя стандартного набора факторов трудового процессе и производственной среды. В частности, зрительная нагрузка, выполняемая при компьютерной игре, оказывает наибольшее воздействие на частотно-временные характеристики зрительного анализатора [14].

В настоящее время подходы к оценке данной ситуации, к сожалению, практически не изменились. Более того новые технические решения становятся причиной появления новых особенностей и проблем. Например. Специфические особенности светодиодов являются причиной специфических жалоб. А именно, появ- ление «глазных мушек». Как известно, это симптом нарушений в стекловидном теле. Жалобы на появление «глазных мушек» чаще всего регистрировались после работы на LCD-мониторах со светодиодной RGB-подсветкой [6].

Принимая во внимание изложенные нюансы, можно констатировать возрастание роли преподавателя, который, естественно, обязан использовать новые научные данные в материалах лекций. Однако, обсуждение ряда новых проблем, требует дополнительных затрат времени также еще и на практических занятиях. Увеличивая плотность практических занятий, необходимого результата добиться крайне сложно, или, точнее, наверное, даже невозможно. Поэтому, необходимость увеличения количества учебного времени для детального рассмотрения и анализа современной научной информации, по обсуждаемой проблеме, вряд ли можно считать предметом для дискуссий.

Оценивая значимость условий зрительной работы в сохранении здоровья современного человека, следует особо отметить важность этого вида деятельности для подрастающего поколения и студенческой молодежи.

\section{А.А. Потапов, М.И. Ежелева}

ГОО ВПО «Донецкий национальный медицинский университет им. М. Горького», г. Донецк

\section{СОВРЕМЕННЫЕ ПРОБЛЕМЫ ОРГАНИЗАЦИИ ЗРИТЕЛЬНОЙ РАБОТЫ В СИСТЕМЕ ОБУЧЕНИЯ НА КАФЕДРАХ ГИГИЕНИЧЕСКОГО ПРОФИЛЯ}

В статье обсуждается специфика преподавания вопросов организации зрительной работы. Акцентируется внимание на гигиенических особенностях новых видов техники и проблемах, связанных с их внедрением. В частности, оцениваются особенности использования светодиодного освещения, видеодисплейных терминалов и ридеров. Необходимость расширения объема материала и увеличения времени для преподавания обсуждаемых вопросов обосновы- вается тем, что в условиях современного информационного изобилия даже специалисты далеко не всегда имеют возможность получать объективную информацию о различных новых видах современных технических устройств.

Ключевые слова: организация зрительной работы, светодиодное освещение, видеодисплейные терминалы, ридеры.

\section{A. Potapov, M. Yezheleva}

\section{SEI HPE «M. Gorky Donetsk National Medical University», Donetsk}

\section{MODERN PROBLEMS OF THE ORGANIZATION OF VISUAL WORK IN THE SYSTEM OF EDUCATION AT THE HYGIENIC PROFILE DEPARTMENTS}

The article discusses the specifics of teaching the organization of visual work. Attention is focused on the hygienic features of new types of equipment and the problems associated with their introduction. In particular, the features of using LED-based lighting, video display terminals and readers are evaluated. The need to expand the volume of material and increase the time for teaching the issues discussed is justified by the fact that, in the conditions of modern information abundance, even specialists do not always have the opportunity to receive unbiased information about various new types of modern technical devices.

Key words: organization of visual work, LED-based lighting, video display terminals, readers. 


\section{ЛИТЕРАТУРА}

1. Степанова М.И., Сазанюк З.И., Лапонова Е.Д., Лашнева И.П., Березина Н.О. Гигиеническая регламентация занятий школьников за компьютером. Здоровье населения и среда обитания. 2012; 8: 25-27.

2. Кучма В.Р., Сухарева Л.М., Текшева Л.М., Степанова М.И., Сазанюк 3.И. Гигиенические аспекты применения светодиодных источников света для общего освещения в школах. Гигиена и санитария. 2013; 5: 27-31.

3. Текшева Л.М., Надеждин Д.С. Состояние нервнопсихической сферы младших школьников в течение учебного дня при люминесцентном и светодиодном освещении учебного кабинета. Гигиена и санитария. 2014; 4: 123-127.

4. Дейнего В.Н., Капцов В.А. Гигиена зрения при светодиодном освещении. Современные научные представления. Гигиена и санитария. 2014; 5: 54-58.

5. Капцов В.А., Дейнего В.Н. Синий свет светодиодов новая гигиеническая проблема. Анализ риска здоровью. 2016; 1 (13): 15-25.

6. Дейнего В.Н., Капцов В.А. Свет энергосберегающих и светодиодных ламп и здоровье человека. Гигиена и санитария. 2013; 6: 81-84.

7. Видеодисплейные терминалы и здоровье пользователей: Пер. с англ. ВОЗ: Женева; 1989. 150.

8. Матюхин В.В., Шардакова Э.Ф., Ямпольская Е.Г., Елизарова В.В. Обоснование физиолого-эргономических мероприятий по снижению развития зрительного утомления при работе с видеодисплейными терминалами. Анализ риска здоровью. 2017; 3: 66-75.

9. Кочина М.Л., Яворский А.В., Маслова Н.М. Особенности влияния разных видов визуальной нагрузки на функциональное состояние зрительной системы детей и подростков. Вісник ВДНЗУ «Українська медична стоматологічна академія». 2017; 17, 1 (57): 112-116.

10. Догуревич О.А., Сугробова Г.А. Влияние работы на ПЭВМ с разными видами информации на психофизиологическое состояние подростков. Известия высших учебных заведений. Поволжский регион. Естественные науки. 2017; 4 (20): 65-73.

11. Потапов О.А. Гігієно-фізіологічна оптимізація праці операторів ЕОМ з відеотерміналами. Дисертація на здобуття наукового ступеня канд. мед. наук. Київ; 1999: 195.

12. Кучма В.Р., Текшева Л.М., Вятлева О.А., Курганский А.М. Физиолого-гигиеническая оценка восприятия информации с электронного устройства для чтения (ридера). Гигиена и санитария. 2013; 1: 22-26.

13. Петренко А.О. Гигиеническая оценка эффективности использования школьниками ридеров. Здоровье населения и среда обитания. 2015; $1: 38-42$.

14. Тимерханов Р.И., Ахмадеев Р.Р., Кошелев Д.И., Еникеев Д.А. Показатели хроматической критической частоты слияния мельканий при кратковременой компьютерной зрительной нагрузке различного характера. Медицинский вестник Башкортостана. 2014; 9 (5): 92-95.

\section{REFERENCES}

1. Stepanova M.I., Sazanjuk Z.I., Laponova E.D., Lashneva I.P., Berezina N.O. Hygienic regulation of classes for schoolchildren at the computer. Public health and habitat. 2012; 8: 25-27 (in Russian).

2. Kuchma V.R., Suhareva L.M., Teksheva L.M., Stepanova M.I., Sazanjuk Z.I. Hygienic aspects of the use of LED light sources for general lighting in schools. Gigiena i sanitarija. 2013; 5: 27-31 (in Russian).

3. Teksheva L.M., Nadezhdin D.S. The state of the neuropsychic sphere of younger schoolchildren during the school day with the fluorescent and LED lighting of the classroom. Gigiena i sanitarija. 2014; 4: 123-127 (in Russian).

4. Dejnego V.N., Kapcov V.A. Hygiene of vision at LED lighting. Modern scientific presentation. Gigiena i sanitarija. 2014; 5: 54-58 (in Russian).

5. Kapcov V.A., Dejnego V.N. Blue LED light is a new hygienic problem. Health risk analysis. 2016; 1 (13): 15-25 (in Russian).

6. Dejnego V.N., Kapcov V.A. Light energy saving and LED lamps and human health. Gigiena i sanitarija. 2013; 6: 8184. (in Russian)

7. Video display terminals and user health. VOZ: Zheneva; 1989. 150.

8. Matjuhin V.V., Shardakova Je.F., Jampol'skaja E.G., Elizarova V.V. Justification of physiological and ergonomic measures to reduce the development of visual fatigue when working with video display terminals. Health risk analysis. 2017; 3: 66-75 (in Russian).

9. Kochina M.L., Javorskij A.V., Maslova N.M. Features of the influence of different types of visual load on the functional state of the visual system of children and adolescents. Visnik VDNZU «Ukrains'ka medichna stomatologichna akademija». 2017; 17, 1 (57): 112-116. (in Russian)

10. Dogurevich O.A., Sugrobova G.A. The influence of work on computers with different types of information on the psycho-physiological state of adolescents. Izvestija vysshih uchebnyh zavedenij. Povolzhskij region. Estestvennye nauki. 2017; 4 (20): 65-73 (in Russian).

11. Potapov O.A. Hygienic and physiological optimization of the work of computer operators with video terminals. Disertacija na zdobuttja naukovogo stupenja kand. med. nauk. Kiïv; 1999: 195 (in Russian).

12. Kuchma V.R., Teksheva L.M., Vjatleva O.A., Kurganskij A.M. Physiological-hygienic assessment of information perception from an electronic reader (reader). Gigiena $i$ sanitarija. 2013; 1: 22-26 (in Russian).

13. Petrenko A.O. Hygienic assessment of the effectiveness of the use of schoolchildren readers. Zdorov'e naselenija $i$ sreda obitanija. 2015; 1: 38-42 (in Russian).

14. Timerhanov R.I., Ahmadeev R.R., Koshelev D.I., Enikeev D.A. Indicators of the chromatic critical frequency of flicker fusion with short-term computer visual load of a different nature. Medicinskij vestnik Bashkortostana. 2014; 9 (5): $92-95$ (in Russian). 